\title{
Fabrication of Lignocellulosic Biomass Paper Containing Nanofibrillated Biomass
}

\author{
Samarthya Bhagia, ${ }^{\mathrm{a}}$ John R. Dunlap, ${ }^{\mathrm{b}}$ Mohammed Zahid A. Khuraishi, ${ }^{\mathrm{c}}$ \\ Richard R. Lowden, ${ }^{\mathrm{d}}$ Wellington Muchero, ${ }^{\mathrm{e}}$ Uday K. Vaidya, ${ }^{\mathrm{c}}$ Yunqiao Pu, and \\ Arthur J. Ragauskas f,g,h,*
}

\begin{abstract}
Fibrillated cellulose has been frequently used for making nanopapers and thin films. However, limited work has been carried out in the construction of such materials using native lignocellulosic biomass. Making papers from fibrillated biomass allows complete utilization of whole plant material and may reduce chemical and energy consumption. Ultra-friction grinding was used to directly fibrillate knife-milled poplar into micro- to nano-sized biomass fibers. Papers were made using the fibrillated biomass containing nanofibrillated biomass and their mechanical properties were tested. Biomass papers made via press-drying had higher tensile strength than papers made by air-drying. A higher press-drying temperature of $180^{\circ} \mathrm{C}$ produced stronger papers than at $150{ }^{\circ} \mathrm{C}$. Guar gum substantially increased the strength of the press-dried papers in comparison to cationic starch. Press-drying increased the thermogravimetric peak decomposition temperature by $13^{\circ} \mathrm{C}$ in comparison to air-drying.
\end{abstract}

Keywords: Poplar; Biomass; Fibrillation; Nanopaper

Contact information: a: Biosciences Division, Oak Ridge National Laboratory, Oak Ridge, TN 37831, USA; b: Advanced Microscopy and Imaging Center, University of Tennessee, Knoxville, TN, 37996, USA; c: Fibers and Composites Manufacturing Facility, Department of Mechanical, Aerospace and Biomedical Engineering, University of Tennessee, Middle Drive, Knoxville, TN 37996, USA; d: Materials Science and Technology Division, Oak Ridge National Laboratory, Oak Ridge, TN 37831, USA; e: Plant Systems Biology Group, Biosciences Division, Oak Ridge National Laboratory, Oak Ridge, TN, 37831, USA; f: Department of Chemical and Biomolecular Engineering, University of Tennessee, Knoxville, TN 37996, USA; g: Joint Institute of Biological Sciences, Biosciences Division, Oak Ridge National Laboratory, Oak Ridge, TN 37831, USA; h: Center for Renewable Carbon, Department of Forestry, Wildlife, and Fisheries, University of Tennessee Institute of Agriculture, Knoxville, TN 37996, USA;

* Corresponding author: aragausk@utk.edu

\section{INTRODUCTION}

Several studies have investigated fibrillation of kraft, sulfite, or thermomechanical pulp by refining followed by high-pressure homogenization, cryocrushing, or ultra-friction grinding through an ultrafine friction grinder to produce micro- or nano-fibrillated cellulose (MFC or NFC) (Siró and Plackett 2010). Among its many applications, NFC can be used for making pure cellulose nanopaper and as a film additive or coating material for thin film materials applications, such as biodegradable packaging and flexible printed electronics (Hoeng et al. 2016), because of its ability to improve physical properties of the materials. However, pulp production, which is primarily carried out today by the kraft process (Van Heiningen 2006), consumes chemicals and energy. Pulp yields from wood vary between $42 \%$ and 55\% depending on the wood types and the process conditions (MacLeod 2007). Instead, if micro- or nano-fibrillated biomass (NFB) can be produced directly by fibrillation of wood and other lignocellulosic biomass, it can be successfully fabricated into 
lignocellulosic biomass paper. Thus, NFB could prepared without capital-intensive manufacturing protocols.

Lignocellulosic nanofibers (LCNF) that contain residual hemicellulose and lignin have been prepared from chemical pulps followed by mechanical treatment (Morales et al. 2014; Espinosa et al. 2016, 2017; Sánchez et al. 2016). The LCNF have been used as additives in fiberboards (Diop et al. 2017), paper (Delgado-Aguilar et al. 2016; Tarrés et al. 2017), plastics (Iwamoto et al. 2014), and resins (Nair et al. 2017). Whole biomass nanofibers that contain high lignin content have only recently been produced for making nanopapers. Ultra-friction grinding of mechanical pulp (spruce groundwood) has been carried out to obtain wood nanofibers (WNF) to make lignocellulosic nanopapers (Visanko et al. 2017; Sethi et al. 2019). However, the constitution of papers from fibers recovered from ultra-friction grinding of knife-milled biomass without prior mechanical pulping has not been performed. Moreover, certain additives are often added to commercial pulps to modify strength, fines retention, surface charge, or energy consumption in papermaking. Polysaccharide gums can be added to improve hydrogen bonding and cationic starch can be added for neutralizing the anionic charge on fiber surface to improve the strength of paper (Marton 1996). However, such additives have not been investigated in making micro- or nanofibrillated whole biomass papers.

Therefore, the methods of making biomass papers and their mechanical properties using material obtained directly from ultra-friction grinding of milled biomass are investigated in this work. Because grinding produced fibers from the $45 \mu \mathrm{m}$ to $5 \mathrm{~nm}$ range, the term 'biomass paper' instead of 'biomass nanopaper' is used in this work. Mechanical strength of air-dried papers and hot-press dried papers at $150{ }^{\circ} \mathrm{C}$ and $180{ }^{\circ} \mathrm{C}$ were compared. Guar gum (galactomannan) and cationic starch were added to see their effect on the mechanical properties of biomass papers. The biomass papers were characterized by imaging and thermogravimetry.

\section{EXPERIMENTAL}

\section{Materials}

Poplar (GW9947S) used in this study was provided by the Center for Bioenergy Innovation (CBI) (Oak Ridge, TN, USA), a US DOE Biological and Environmental Research (BER) Center, as part of the genome-wide association study (GWAS) dataset in the Biosciences Division at Oak Ridge National Laboratory (Oak Ridge, TN, USA). The poplar was debarked using an angle grinder (Dewalt, Baltimore, MD, USA) and cut into 25- to 50-mm transverse sections using a miter saw. The sections were broken into several pieces using a chisel and hammer, and knife-milled (Wiley Mill Model 4; Thomas Scientific, Swedesboro, NJ, USA) through a 1-mm screen. Compositional analysis was performed by two-step acid hydrolysis NREL procedure (Sluiter et al. 2012; Bhagia et al. 2016). The poplar was composed of $42.1 \%$ glucan, $19.7 \%$ xylan, $20 \%$ acid insoluble lignin, and $4.1 \%$ acid soluble lignin (Bhagia and Ragauskas 2020). Guar gum (GU110, FCC, 85.16\% galactomannan) was purchased from Spectrum Chemical Mfg. Corp. (New Brunswick, NJ, USA). Cationic starch (CHARGEMASTER ${ }^{\circledR}$ L340, pre-gelatinized starch, DS 0.1828) was provided by Grain Processing Corporation in Muscatine, IA, USA. 


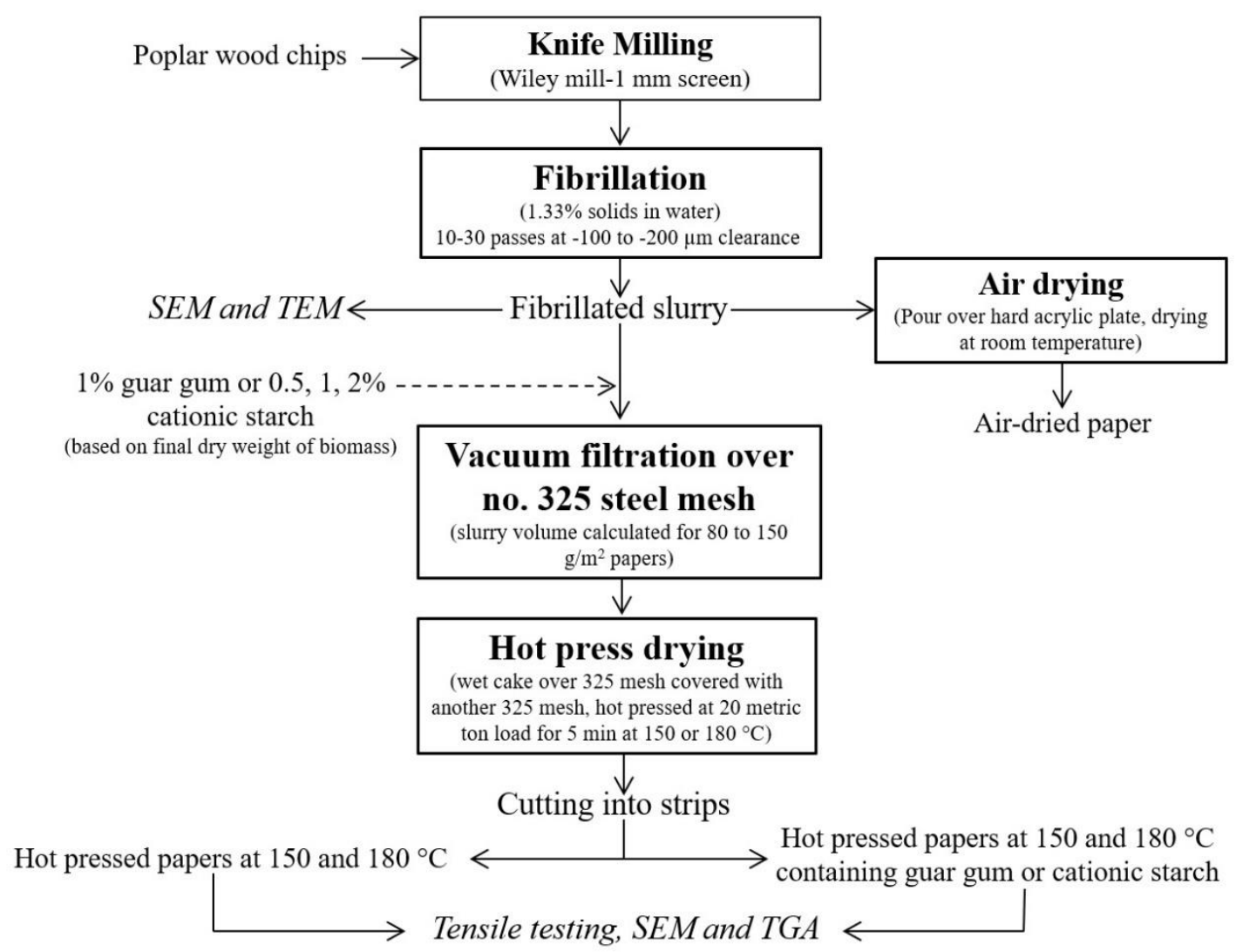

Fig. 1. Experimental workflow

\section{Fibrillation of $1 \mathrm{~mm}$-milled Poplar}

Figure 1 shows the experimental workflow. Fibrillation of the $1 \mathrm{~mm}$ knife-milled poplar was performed by grinding in an ultra-friction grinder (super mass collider) (MKCA6-5J; Masuko Sangyo Co., Ltd. Kawaguchi, Saitama, Japan). Approximately $20 \mathrm{~g}$ of milled poplar and $1.5 \mathrm{~L}$ of water were added in a bucket as the charge for fibrillation in contact-grinding mode. The collider gauge handle that was used for setting the clearance between the grinders had 10 major and 10 minor graduations. One major graduation is assumed to set the clearance approximately to $100 \mu \mathrm{m}$ as indicated by the manufacturer. The "motion zero-point", which indicated that the grinders in motion were nearly touching each other, was set at the zero mark on the screw handle when the slightest sound of vibration of grinders was heard. Initially, 10, 20, 30, and 40 passes (recycles) at $-100 \mu \mathrm{m}$ clearance, and 30 passes at $-200 \mu \mathrm{m}$ clearance of poplar slurry at room temperature were carried out to see the effect of passes and clearance to decide suitable conditions. The scanning electron microscopy (SEM) images (Fig. 2) show that beyond a certain number of passes the clearance between the static and rotary grinder of the super mass collider was the critical controller of fiber size. Therefore, 20 passes at a setting of $-200 \mu \mathrm{m}$ was chosen for preparing fibers for making biomass papers.

Water was heated to $100{ }^{\circ} \mathrm{C}$ in a steel bucket using an immersion heater (Heat-OMatic $500 \mathrm{~W}$, Ulanet, Bristol, CT, USA) and passed once to heat the friction grinder. Then, the poplar suspension was heated to $100{ }^{\circ} \mathrm{C}$ and recycled 20 times at $-200 \mu \mathrm{m}$ clearance through the friction grinder. The friction generated during grinding maintained the poplar slurry at approximately 75 to $85^{\circ} \mathrm{C}$ between the passes. Because grinding can leave a small 
portion of material that could not pass between the grinding stones in the super mass collider, the poplar slurry was sieved through an ASTM no. 60 mesh screen to remove these particles. In a separate step, a portion of slurry was sieved through a 325 mesh screen to check if there were any particles between Number 325-60 sieve mesh (45 to $250 \mu \mathrm{m}$ ) by running excess tap water. This size range only comprised $5 \%$ of the total biomass solids in the fibrillated slurry. Therefore, these fibers were not removed in making any of the biomass papers except for the two press-drying conditions at $150{ }^{\circ} \mathrm{C}$ and $180{ }^{\circ} \mathrm{C}(325$ to $60 \mathrm{mesh}$ ), meant specifically for studying the effect of making biomass papers only using large-sized fibers in the 325 to 60 mesh range. Because the fibrillated biomass fibers liked to aggregate, the 325 mesh was easily clogged by the smaller-sized fibers and removing the 325 to 60 mesh larger fibers required running excess water through the sieve, which then required a dewatering step to bring the solids concentration to 1 to $2 \%$. Therefore, removing the 325 to 60 mesh fibers was not preferred. Solid concentrations of the fibrillated slurry after 20 passes were determined by drying in aluminum dishes overnight in a convection oven at $105{ }^{\circ} \mathrm{C}$.

\section{Fabrication of Biomass Papers}

Air-dried biomass papers were fabricated by pouring the slurry on a hard acrylic plate $(0.22 \mathrm{~m} \times 0.28 \mathrm{~m})$ and drying for 3 to 4 days at room temperature. The homogenous and flat air-dried papers could easily be removed from the plate. Their corners were cut to remove edge effects. For making papers through press-drying, the wet filtered masses were prepared by vacuum filtration in a Buchner funnel using 325 stainless steel mesh screens. For making pure biomass papers through press-drying, poplar slurries of known weights were poured in glass beakers to make 80 to $150 \mathrm{~g} / \mathrm{m}^{2}$ papers. For making papers containing guar gum or cationic starch, $1 \mathrm{w} / \mathrm{w} \%$ guar gum or $0.5,1$, or $2 \%$ cationic starch based on per unit biomass weight was added to the poplar suspension and mixed with a homogenizer (Ultra-Turrax T25; IKA Works Inc. Wilmington, NC, USA) for $1 \mathrm{~min}$ at the lowest speed setting and keeping the final suspension for $15 \mathrm{~min}$ before filtration. For each paper, ASTM mesh no. 325 (sieve opening $\sim 45 \mu \mathrm{m}$ ) was cut, placed inside the funnel, and water was passed under vacuum to make the mesh stick flat on the funnel base. Then, the vacuum was turned off and a small portion of the slurry was poured over the mesh followed by suction again to form the base network of fibrillated fibers. The remainder of the slurry was poured to complete the filtration. The micro- and nano-sized fibers were retained by first forming a base network of fibers on the steel mesh. The wet cake formed over the mesh was press-dried in a hot press (Carver Auto Series NE automatic hydraulic press, max 30 metric tons, 8 " $\times 8$ " $(20.32 \times 20.32 \mathrm{~cm})$ platens, Wabash, IN, USA). To make the biomass papers, another 325 mesh was cut into a circle to cover the topside of the wet cake. The press was heated to a stable top and bottom platen temperature of $150{ }^{\circ} \mathrm{C}$ or $180{ }^{\circ} \mathrm{C}$. The cake sandwiched between the two 325 mesh circles was placed and the platens were quickly closed, and a timer was started. Within $30 \mathrm{~s}$, the load was increased from 5, to 10 , to 15 , to 20 metric tons followed by keeping the load at 20 tons for $5 \mathrm{~min}$. The diameters of papers were $80 \mathrm{~mm}$, which corresponds to a pressure of $39 \mathrm{MPa}$ (390 bar). The dried papers were peeled off from their lower mesh and cut into strips for tensile testing, imaging and thermogravimetric Analysis (TGA).

\section{Tensile Stress-strain Measurements}

For the measurements, 5 to 7 strips approximately $5 \mathrm{~mm}$ wide were cut from 2 to 3 papers for each condition. Tensile testing was performed on an in-house micro-tensile 
testing machine (MTS, Eden Prairie, MN, USA) in the Materials Science and Technology Division at ORNL. A $25 \mathrm{lb}(111.2 \mathrm{~N})$ load was used, and the gage length was set to 10 $\mathrm{mm}$. The extension rate was set to $0.1 \mathrm{~mm} / \mathrm{s}$, and data were recorded at 10 points $/ \mathrm{s}$. Calculations were made according to TAPPI T494 om-01 (2006). Values were determined from average of 5 replicates of each kind of sample.

\section{Scanning Electron Microscopy (SEM) Analysis}

To see the effect of fibrillation, small quantities of fibrillated suspensions were poured directly onto carbon tapes, glued onto aluminum stubs, and excess sample was skimmed off the carbon tape under a stream of air followed by air-drying. The samples were then sputter coated with gold and imaged at $5 \mathrm{kV}$ on a Zeiss Auriga FIB/SEM (Carl Zeiss Microscopy, White Plains, NY, USA).

\section{Transmission Electron Microscopy (TEM)}

A small drop of poplar suspension resulting from fibrillation at 20 passes at -200 $\mu \mathrm{m}$ was placed on a copper grid with carbon film in a $1000 \mu \mathrm{m}$ hole and allowed to dry at ambient laboratory conditions. The grid was then placed over a drop of UranyLess solution (Cat No. 22409, Electron Microscopy Sciences, Hatfield, PA, USA) for negative staining. The TEM imaging was performed using a Zeiss Libra $200 \mathrm{MC}$ at $80 \mathrm{kV}$ (Carl Zeiss Microscopy, White Plains, NY, USA).

\section{Thermogravimetric Analysis (TGA)}

TGA was carried out on TA Instruments Q50 TGA (New Castle, DE, USA) with $\sim 10 \mathrm{mg}$ sample in platinum pan from 40 to $700{ }^{\circ} \mathrm{C}$ at a linear heating rate of $20{ }^{\circ} \mathrm{C} / \mathrm{min}$ under nitrogen. Data analysis was done with Universal Analysis software (TA Instruments, New Castle, DE, USA). The first derivative was used for finding peak temperatures and $\%$ weight curve was used for calculation of weight change of the two stages.

\section{RESULTS AND DISCUSSION}

An ultra-friction grinder is a device that contains static and rotating grinding stones in which the rotating stone rotates at a high speed $(\sim 1500 \mathrm{rpm})$. High shear and pressure forces fibrillate the material that passes between the grinders (Masuda 1997). Such machines have been used to prepare NFC (Siró and Plackett 2010). The SEM images (Fig. 2) from initial ultra-friction grinding (fibrillation) experiments using $1.33 \%$ milled poplar in water showed that increasing the number of passes (recycles) from 10 to 40 at $-100 \mu \mathrm{m}$ clearance did not reduce fiber size as much as that seen at 30 passes at $-200 \mu \mathrm{m}$ clearance. The SEM images for 30 passes at $-200 \mu \mathrm{m}$ clearance show that fibers were reduced to at least $1 / 5$ in size compared to the fibers resulting from $-100 \mu \mathrm{m}$ clearance (note the scale bars). Thus, after a certain number of passes, the clearance between grinders needed to be low to reduce fiber size. The SEM images (Fig. 2) show bundled fibers due to aggregation tendency of individual fibers on drying and had with widths ranging from $80 \mathrm{~nm}$ to $1.3 \mu \mathrm{m}$.

Visanko et al. (2017) carried out fibrillation of spruce mechanical pulp at 90 to 95 ${ }^{\circ} \mathrm{C}$ to soften lignin and improve fibrillation efficiency. Therefore, fibrillation of poplar for 20 passes at $-200 \mu \mathrm{m}$ clearance under heated conditions was chosen for preparing the fibrillated biomass containing micro- and nanofibers. The initial poplar suspension was heated to near $100{ }^{\circ} \mathrm{C}$, after which heat generated due to friction in the machine kept the 
suspension between 75 to $85^{\circ} \mathrm{C}$. Maintaining the suspension near $100{ }^{\circ} \mathrm{C}$ was not done, as it would have required heating after each pass making the process slow and impractical. The glass transition temperature determined from dynamic mechanical analysis of whole wood in water-saturated conditions was in the 60 to $90^{\circ} \mathrm{C}$ range (Olsson and Salmén 1997) and therefore, grinding in heated conditions can improve separation of biomass fibers. The TEM image in Fig. 3 shows some individual fibers of widths 5 to $7 \mathrm{~nm}$ but several $100 \mathrm{~nm}$ in length. Because one of the dimensions was less than $100 \mathrm{~nm}$ (Kumar and Kumbhat 2016), these fibers can be called nanofibrillated biomass. The fibers stick together when the samples are dried for electron microscopy.

(a)

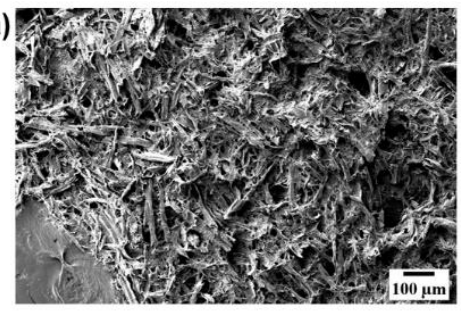

(d)

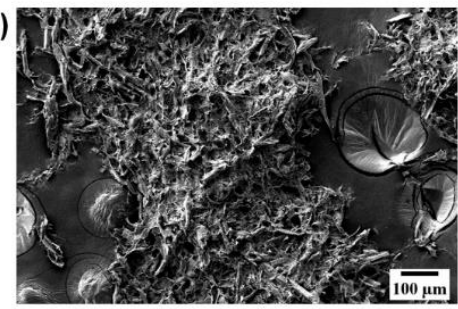

(b)

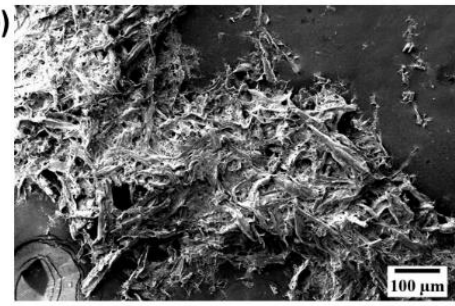

(e)

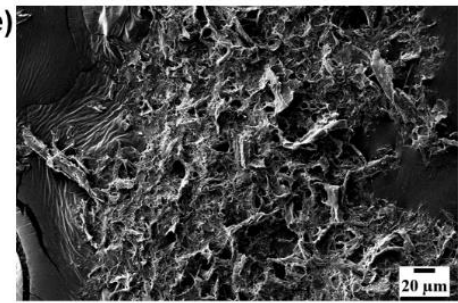

(c)
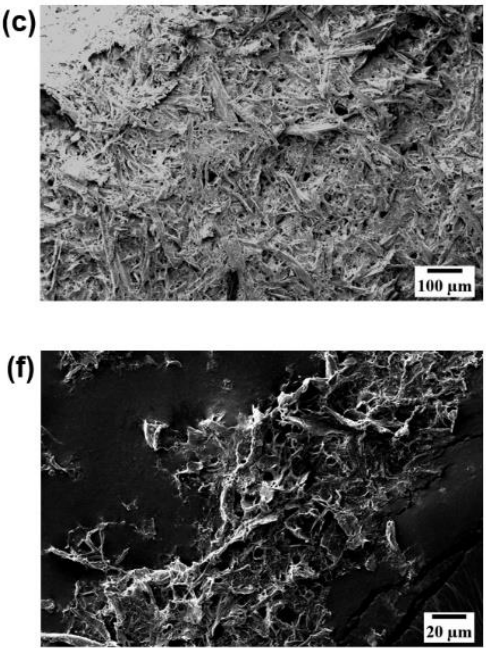

Fig. 2 SEM images of poplar fibrillated at conditions (a) 10 passes at $-100 \mu$ m clearance; (b) 20 passes at $-100 \mu \mathrm{m}$ clearance; (c) 30 passes at $-100 \mu \mathrm{m}$ clearance; (d) 40 passes at $-100 \mu \mathrm{m}$ clearance; and (e) 20 passes at $-200 \mu \mathrm{m}$ clearance (f) 30 passes at $-200 \mu \mathrm{m}$ clearance

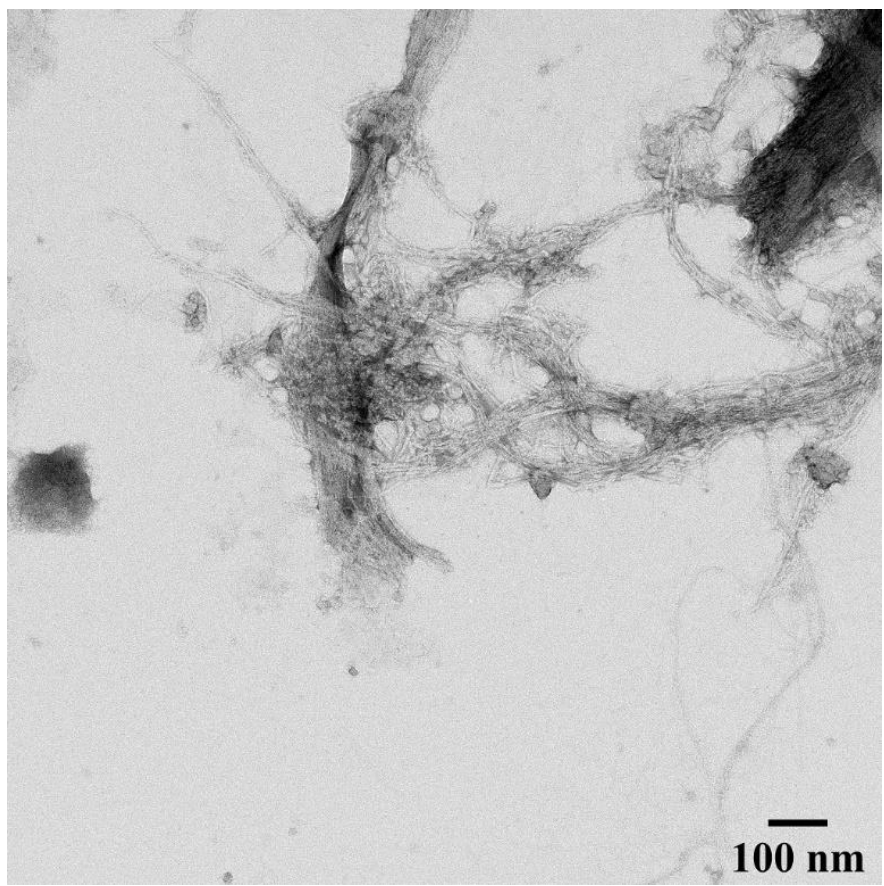

Fig. 3. TEM image of nanofibrillated biomass (NFB) 
Pouring fibrillated biomass slurry directly over a stainless-steel mesh made the filtration complete in less than $1 \mathrm{~min}$ in comparison to using regenerated cellulose, polyvinylidene difluoride, or nylon membranes, which can take a longer time to filter. In either case, the fast filtration of nanofibrillated biomass is a big advantage over nanofibrillated cellulose that can take over an hour to filter (Sethi et al. 2019). The other advantage of directly filtering over the No. 325 mesh is that the mesh can be kept in the hot press, unlike collection over the above-stated membranes that require peeling or sliding of the fragile thin wet biomass cake, which often causes breaks in the thin areas.
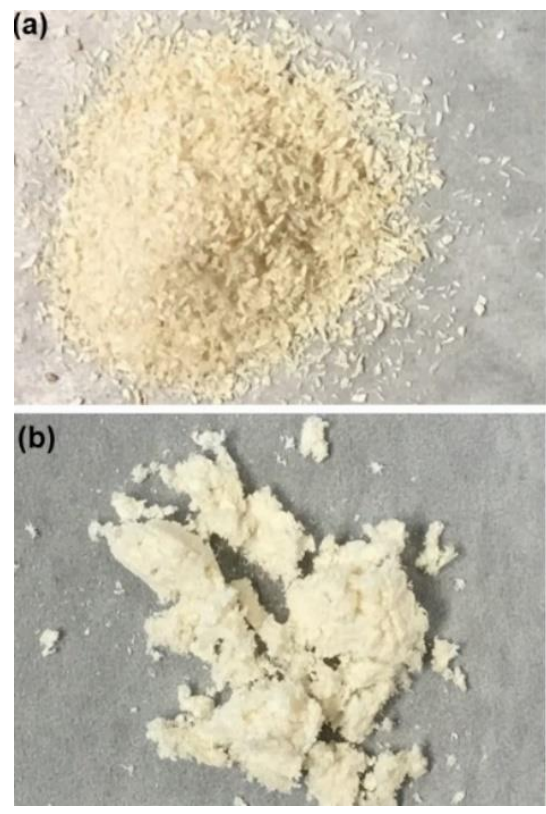
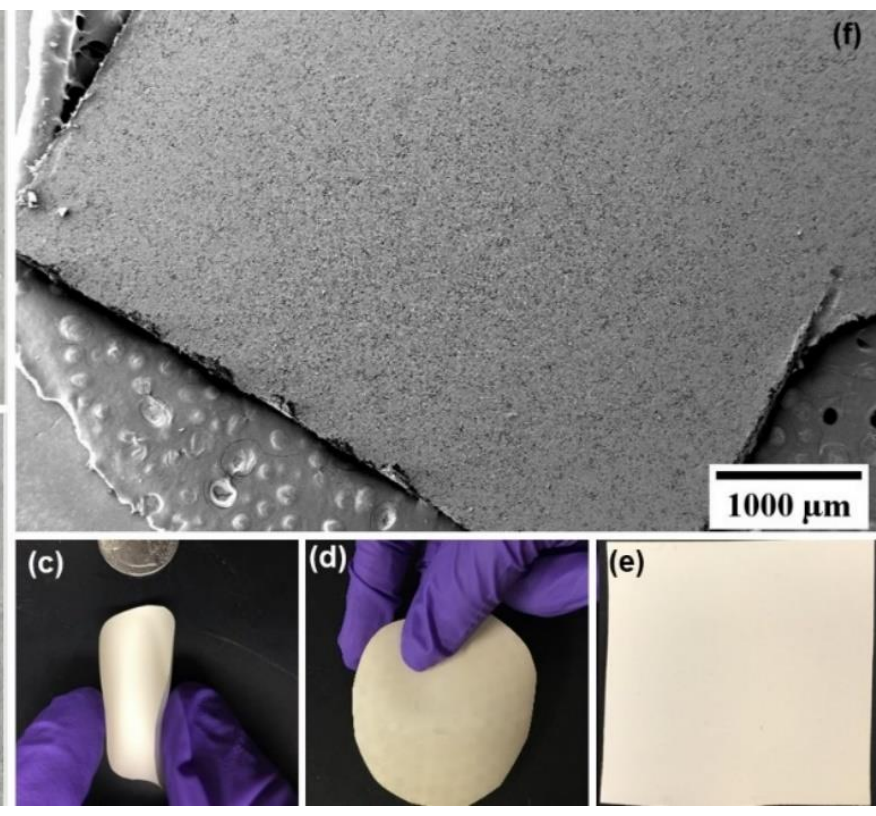

(e)

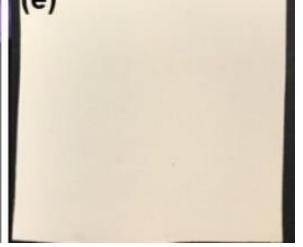

Fig. 4. Images of (a) 1-mm knife-milled poplar; (b) fibrillated poplar after excess water removal; (c to e) biomass paper; and (f) SEM image of the biomass paper

Table 1 shows the mechanical properties determined from tensile force elongation measurements. Tensile strength is defined here as the maximum tensile force per unit width of paper. Tensile index (TI) is tensile strength per unit grammage according to TAPPI T494 om-01 (2006). Young's modulus (linear modulus of elasticity) (MOE) is the slope of the tensile stress (tensile force per unit cross-sectional area) and strain (ratio of change in length to initial length) curve in the elastic region, which gives an estimate of the material's ability to resist elastic deformation. Tensile energy absorption (TEA) is defined here as the area under a force - elongation (change in length) curve per unit mass and is a measure of the toughness of the paper. Press-drying at 150 and $180{ }^{\circ} \mathrm{C}$ at $390 \mathrm{bar}$ (39 $\mathrm{MPa}$ ) for $5 \mathrm{~min}$ roughly increased tensile index 2 to 2.5 times compared to air-dried paper. The percent strain and MOE increased roughly from 1.5 to $2 \%$ and 0.6 to $1.4 \mathrm{GPa}$, respectively. The TEA increased from around 75 to 180 to $240 \mathrm{~mJ} / \mathrm{g}$ on press drying. Pressdrying increased the density in 0.65 to $0.80 \mathrm{~g} / \mathrm{cm}^{3}$ range in comparison to $0.40 \mathrm{~g} / \mathrm{cm}^{3}$ for air-dried paper. This caused an increase in strength, stretch, and toughness of the paper due to lower gaps and higher interaction between the fibers. Press-drying of wet biomass material at high temperatures, such as $150{ }^{\circ} \mathrm{C}$, likely made the hemicellulose and lignin migrate on biomass surface and affect the para-crystalline and amorphous regions of cellulose to achieve better bonding between all components for an overall stronger biomass paper. The increase in TI and TEA by press-drying at $180{ }^{\circ} \mathrm{C}$ compared to $150{ }^{\circ} \mathrm{C}$ showed 
that $180{ }^{\circ} \mathrm{C}$ was better for fabricating stronger biomass papers containing nanofibrillated biomass (NFB). The glass transition temperature of isolated dry lignin is around 170 to 180 ${ }^{\circ} \mathrm{C}$ (Baumberger et al. 2002). At these high platen temperatures of the hot press, the moisture from the wet paper was removed in less than $1 \mathrm{~min}$, while the hot-pressing time was 5 min. Therefore, press-drying at $180{ }^{\circ} \mathrm{C}$ likely allowed better flow of lignin on the fiber surface and hydrophobic interactions among lignin surfaces of fibers bonded them together, resulting in better mechanical strength of the paper.

Table 1. Mechanical Properties of the Lignocellulosic Biomass Papers

\begin{tabular}{|c|c|c|c|c|}
\hline Sample Type & $\begin{array}{c}\text { Tensile } \\
\text { Index (Nm/g) }\end{array}$ & $\begin{array}{c}\text { Stretch } \\
\text { (Strain \% } \\
\text { at break) }\end{array}$ & $\begin{array}{c}\text { Modulus of } \\
\text { Elasticity } \\
\text { (GPa) }\end{array}$ & $\begin{array}{c}\text { Tensile } \\
\text { Energy } \\
\text { Absorption } \\
\text { (mJ/g) }\end{array}$ \\
\hline Air-dried biomass paper & $11.01(0.39)$ & $1.54(0.09)$ & $0.56(0.08)$ & $76(25)$ \\
\hline PD at $150{ }^{\circ} \mathrm{C}$ & $19.38(0.48)$ & $2.05(0.06)$ & $1.34(0.03)$ & $180(6)$ \\
\hline PD at $150^{\circ} \mathrm{C}+1 \%$ guar & $25.6(0.29)$ & $2.19(0.07)$ & $1.15(0.02)$ & $245(19)$ \\
\hline $\begin{array}{c}\text { PD at } 150^{\circ} \mathrm{C}(\text { sieved } \\
\text { between } 45 \text { to } 250 \mu \mathrm{m})^{*}\end{array}$ & $11.73(0.5)$ & $1.98(0.16)$ & $0.96(0.01)$ & $73(1)$ \\
\hline PD at $150^{\circ} \mathrm{C}+0.5 \% \mathrm{CS}$ & $21.38(0.4)$ & $2.15(0.06)$ & $1.10(0.15)$ & $187(13)$ \\
\hline $\mathrm{PD}$ at $150^{\circ} \mathrm{C}+1 \% \mathrm{CS}$ & $20.22(0.18)$ & $2.19(0.23)$ & $1.12(0.04)$ & $229(5)$ \\
\hline $\mathrm{PD}$ at $150^{\circ} \mathrm{C}+2 \% \mathrm{CS}$ & $18.76(0.19)$ & $2.45(0.03)$ & $1.36(0.03)$ & $141(18)$ \\
\hline $\mathrm{PD}$ at $180{ }^{\circ} \mathrm{C}$ & $27.72(0.08)$ & $2.35(0.03)$ & $1.46(0.11)$ & $239(1)$ \\
\hline $\mathrm{PD}$ at $180^{\circ} \mathrm{C}+1 \%$ guar & $29.68(1.4)$ & $2.62(0.16)$ & $1.20(0.01)$ & $252(2)$ \\
\hline $\begin{array}{c}\mathrm{PD} \text { at } 180^{\circ} \mathrm{C}(\mathrm{sieved} \\
\text { between } 45 \text { to } 250 \mu \mathrm{m})^{*}\end{array}$ & $18.03(1.21)$ & $2.53(0.09)$ & $0.91(0.01)$ & $185(10)$ \\
\hline $\mathrm{PD}$ at $180^{\circ} \mathrm{C}+0.5 \% \mathrm{CS}$ & $20.94(0.1)$ & $2.19(0.03)$ & $1.02(0.04)$ & $185(5)$ \\
\hline $\mathrm{PD}$ at $180^{\circ} \mathrm{C}+1 \% \mathrm{CS}$ & $22.99(0.75)$ & $2.29(0.06)$ & $1.19(0.05)$ & $200(13)$ \\
\hline $\mathrm{PD}$ at $180^{\circ} \mathrm{C}+2 \% \mathrm{CS}$ & $18.74(0.21)$ & $2.12(0.1)$ & $1.10(0.02)$ & $147(11)$ \\
\hline
\end{tabular}

PD: Press-drying; CS: cationic starch; *: The fibrillated material contained about $5 \%$ of larger fibers in the 45 to $250 \mu \mathrm{m}$ range. These conditions represent paper made only from these larger fibers obtained over 60 mesh by sieving. Numbers in parentheses represent standard deviation

To see the effect of making biomass papers using larger sized fibers, the $5 \%$ of the total poplar slurry that contained 45 to $250 \mu \mathrm{m}$ (325 to $60 \mathrm{mesh}$ ) fibers were isolated. The lower mechanical properties of the papers made from these fibers by press drying at 150 and $180^{\circ} \mathrm{C}$ (Table 1) suggest that lowering the fiber size increased strength of the biomass paper. This is likely due to higher surface area of the smaller size fibers that produces better hydrogen and Van der Waals bonding, compared to larger fibers that are oriented randomly and have more defects that lead to failure at lower tensile loads.

Vegetable gums like guar gum (galactomannan) have been added to cellulose pulps to increase the dry strength of cellulose papers (Leech 1954). Galactomannan is a highly hydrophilic polysaccharide and forms an extensive network of hydrogen bonds. Table 1 shows that the addition of $1 \%$ guar (based on per unit mass of biomass on dry basis) increased the TI and TEA of paper press-dried at $150{ }^{\circ} \mathrm{C}$. This was likely due to increase in hydrogen bonded network among the biomass polymers. However, the increase in strength was marginal when the material was press-dried at $180^{\circ} \mathrm{C}$. The reason for this can only be speculated at this point but could be due to the breakdown of galactomannan chains 
at $180{ }^{\circ} \mathrm{C}$, resulting in a lower improvement in strength. The pulping process can lead to oxidation of some hydroxyl groups, and the resulting carboxylic groups show a negative surface charge. Adsorption of cationic starch can result in electrostatic attractions and make a better bonded paper (Marton 1996). It was envisioned that because carboxylic groups in biomass might cause electrostatic repulsion (Van de Steeg et al. 1993), the addition of cationic starch might improve bonding between fibers, similar to that seen in cellulose pulps. However, 0.5 and $1 \% \mathrm{CS}$ did not improve the mechanical strength of the press-dried papers. In fact, addition of $2 \% \mathrm{CS}$ reduced the TI and TEA. This was likely due to excess positive charge that caused electrostatic repulsion among the fibers. This suggests that it is the hydrophobic surfaces of lignin that reduce the strength between fibers, rather than electrostatic repulsion in comparison to nanofibrillated cellulose fibers that can form extensive hydrogen bonding and make extremely strong nanocellulose papers or films.

The 2.0 to $2.4 \%$ strain and 1.1 to $1.4 \mathrm{GPa}$ Young's modulus were close among the press-dried papers. Unoxidized fibrillated cellulose papers can bear $105 \mathrm{MPa}$ maximum tensile stress, $4.05 \%$ strain at break, and have a $6.5 \mathrm{GPa}$ Young's modulus (Kumar et al. 2014). Rojo et al. (2015) studied fibrillated cellulose nanopapers using sulfite-ethanol pulp that contained approximately 2, 4, and 14\% residual lignin along with lignin-free kraft pulp. They found that maximum tensile stress dropped from $164 \mathrm{MPa}$ of kraft pulp to 116 $\mathrm{MPa}$ for the $14 \%$ lignin containing pulp. In contrast, Visanko et al. (2017) reported 103 $\mathrm{MPa}$ tensile strength, $6 \mathrm{GPa}$, and 3.5\% strain from the press-drying of wood nanofibers at $150{ }^{\circ} \mathrm{C}$. The higher mechanical strength of the nanopapers reported (Visanko et al. 2017) is likely due to better size reduction and higher percentage of nano-sized fibrillated biomass. This demonstrates that mechanical pulping followed by ultra-friction grinding achieves better fibrillation of lignocellulosic biomass than the direct ultra-friction grinding of knife-milled biomass particles.

Another study (Horseman et al. 2017) produced lignocellulosic nanofibers by thermomechanical pulping (TMP) of spruce followed by fibrillation in ultra-friction grinder. They report $\sim 25 \mathrm{GPa}$ Young's modulus of the film made from LCNF, which is at least four times higher than that reported by Visanko et al. (2017). This is likely because fibrillation was performed for 1.5 to $3 \mathrm{~h}$, which produced more fibers at the nanoscale. Grinding operations are energy-intensive, and although fibrillation can be improved by increasing grinding time, the cost of such fibers can prohibit their application in composites. In this study, fibrillation at 20 passes was completed within 5 to $7 \mathrm{~min}$ of grinding time. The methods in this work show a way of producing nanofibrillated biomass without employing TMP. They can be less expensive, as the capital investment for TMP equipment is not required and applicable on a smaller scale. A previous study carried out power measurement studies on LCNF production from untreated switchgrass and liquid hot water pretreated switchgrass using the same fibrillation equipment (Xu et al. 2020). They found that untreated switchgrass consumed $\sim 20 \mathrm{KWh} / \mathrm{kg}$ electricity at 18 passes. Considering commercial electricity cost of $10 \mathrm{US}$ cents $/ \mathrm{kWh}$, this amounts to $\$ 2 / \mathrm{kg}$ biomass. In comparison, bleached kraft pulps can consume higher energy on fibrillation ( 27 to $49 \mathrm{kWh} / \mathrm{kg}$ ) (He et al. 2018) due to the higher viscosity from more hydrogen bonding of cellulose-rich material with water unlike whole biomass that contains lignin. Since the suspensions have to be dilute in fibrillation processes, dewatering cost and recycling of water are important for commercial feasibility. Furthermore, it is clear that a thorough study is needed to accurately quantify fiber dimensions, size distribution based on mass, and counting-based size distributions to fully interpret how grinding methods and severity affect the amount of fibers that can be classified as 'nanoscale.' The TEM method is the 
preferred choice to see fibers at the nanoscale; however, it requires drying of fibers that makes them bundle together and makes size determination difficult. Currently, no study exists that captures the complete size distribution of biomass fibers produced by the fibrillation techniques.

Thermogravimetric analysis was carried out to see any differences in thermal stability of biomass and biomass papers. A peak near $100{ }^{\circ} \mathrm{C}$ represents evaporation of water. The 230 to $450{ }^{\circ} \mathrm{C}$ range is known as the active pyrolysis region (Gašparovič et al. 2010). The shoulder and major peak can be categorized as two stages in this region (Fig. $5)$.

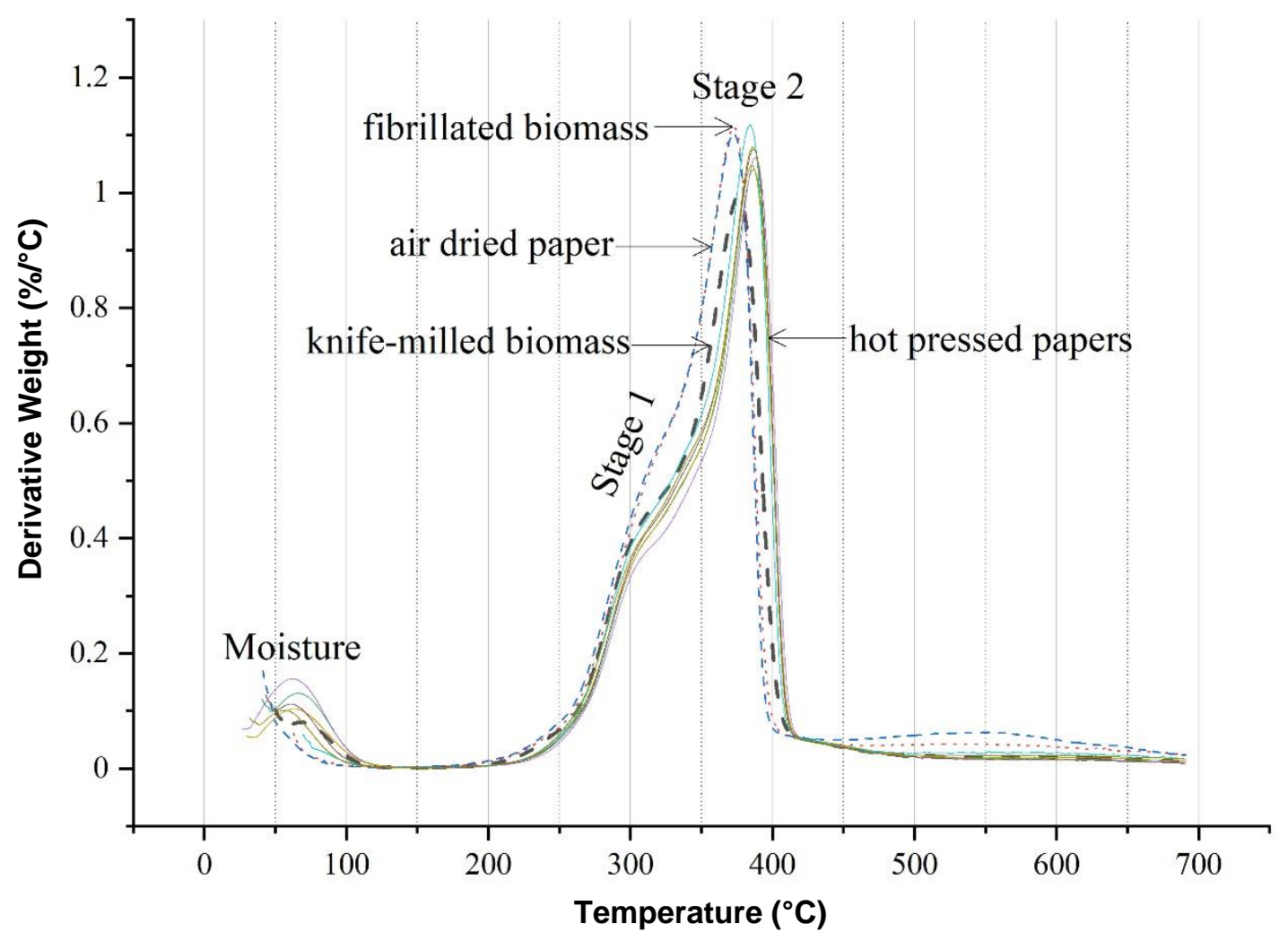

Fig. 5. Thermogravimetric curves of first derivative of weight change in $40-700{ }^{\circ} \mathrm{C}$ range at 20 ${ }^{\circ} \mathrm{C} / \mathrm{min}$ for knife-milled biomass, freeze-dried fibrillated biomass (200 passes at $-200 \mu \mathrm{m}$ ) and hot pressed papers listed in Table 2

The order of degradation of biomass components has been suggested to follow the order: hemicellulose>cellulose>lignin. While all three biomass components decompose into gaseous products in both stages, stage 1 has been linked more to hemicellulose and cellulose decomposition and the stage 2 to lignin decomposition (Bodîrlău et al. 2007). The peak temperatures of stages 1 and 2 for poplar biomass and papers were 298 to $307{ }^{\circ} \mathrm{C}$ and 373 to $388{ }^{\circ} \mathrm{C}$, respectively. The weight loss change of both stages of hot pressed pressed papers (11 to $12.5 \%$ stage 1,42 to $47 \%$ stage 2 ) was lower than that of air-dried paper and freeze-dried fibrillated biomass (22\% stage 1,51 to $52 \%$ stage 2$)$. This is probably due to better bonding among the fibers as press-drying compacts the fibers together (paper density: 0.65 to $0.8 \mathrm{~g} / \mathrm{cm}^{3}$ ) in comparison to air-drying (paper density: 0.4 $\left.\mathrm{g} / \mathrm{cm}^{3}\right)$. The increase in peak temperature of stage 2 of press-dried papers (384 to $388{ }^{\circ} \mathrm{C}$ ) 
in comparison to air-dried paper and freeze-dried fibrillated biomass $\left(373{ }^{\circ} \mathrm{C}\right)$ is indicative of migration and bonding of lignin among the fiber surfaces. On the other hand, $1 \%$ guar gum or cationic starch had no effect on the temperatures or weight. These data indicate that press drying improves the thermal stability of the papers.

Table 2. Thermogravimetric Data of the Active Pyrolysis Stages of Biomass and Papers

\begin{tabular}{|c|c|c|c|c|}
\hline \multirow[t]{2}{*}{ Sample } & \multicolumn{2}{|c|}{$1^{\text {st }}$ Stage } & \multicolumn{2}{|c|}{$2^{\text {nd }}$ Stage } \\
\hline & $\begin{array}{c}\text { Peak } \\
\text { temperature } \\
\left({ }^{\circ} \mathrm{C}\right)\end{array}$ & $\begin{array}{l}\% \text { weight } \\
\text { change of } \\
\text { the stage }\end{array}$ & $\begin{array}{c}\text { Peak } \\
\text { temperature } \\
\left({ }^{\circ} \mathrm{C}\right)\end{array}$ & $\begin{array}{l}\% \text { weight } \\
\text { change of } \\
\text { the stage }\end{array}$ \\
\hline knife-milled poplar & 298 & 15 & 376 & 50 \\
\hline $\begin{array}{c}\text { freeze-dried fibrillated biomass } \\
(200 \text { passes at }-200 \mu \mathrm{m})\end{array}$ & 307 & 22 & 373 & 51 \\
\hline air-dried paper & 305 & 22 & 373 & 52 \\
\hline \multicolumn{5}{|c|}{ hot pressed papers at 150 and $180^{\circ} \mathrm{C}$} \\
\hline $150^{\circ} \mathrm{C}$ pure & 300 & 12 & 387 & 44 \\
\hline $150{ }^{\circ} \mathrm{C}, 1 \%$ guar & 300 & 12 & 388 & 42 \\
\hline $150^{\circ} \mathrm{C}, 1 \%$ cationic starch & 298 & 11 & 386 & 44 \\
\hline $180^{\circ} \mathrm{C}$ pure & 298 & 12 & 384 & 47 \\
\hline $180{ }^{\circ} \mathrm{C}, 1 \%$ guar & 301 & 12.5 & 387 & 42 \\
\hline $180^{\circ} \mathrm{C}, 1 \%$ cationic starch & 298 & 14 & 386 & 44 \\
\hline
\end{tabular}

\section{CONCLUSIONS}

1. Ultra-friction grinding of poplar produced micro- and nanofibrillated biomass was used to make biomass paper. These papers made from direct ultra-friction grinding of knifemilled biomass were less mechanically strong compared to those produced through mechanical pulping followed by ultra-friction grinding. This was likely due to smaller fraction of nano-sized fibrillated biomass in the slurry produced by direct ultra-friction grinding.

2. Press-drying at $150{ }^{\circ} \mathrm{C}$ and $180{ }^{\circ} \mathrm{C}$ resulted in a large improvement in the tensile strength of biomass papers compared to air-drying, and $180^{\circ} \mathrm{C}$ increased mechanical strength compared to $150{ }^{\circ} \mathrm{C}$.

3. Guar gum addition substantially improved the tensile properties of press-dried papers as compared to cationic starch addition.

4. Press drying increased the thermal stability of papers in comparison to air-drying as peak decomposition temperature increased by $\sim 13{ }^{\circ} \mathrm{C}$, which was probably due to better bonding of lignin among fiber surfaces.

\section{ACKNOWLEDGMENTS}

The authors thank the Joint Institute of Advanced Materials (JIAM) for use of SEM and TEM facilities. We thank Prof. Siqun Wang and his group members Kaimeng Xu and 
Jianhua Lyu at Center for Renewable Carbon, University of Tennessee, Knoxville (USA) for availability and training on Masuko supermasscollider. We also thank the Fiber and Composites Manufacturing Facility (FCMF) at the University of Tennessee, Knoxville (USA) for use of the Carver hot press.

This research was funded by the Laboratory Directed Research and Development Program of Oak Ridge National Laboratory, managed by UT-Battelle, LLC, for the U. S. Department of Energy under Contract DE-AC05-00OR22725. The United States Government retains and the publisher, by accepting the article for publication, acknowledges that the United States Government retains a non-exclusive, paid-up, irrevocable, world-wide license to publish or reproduce the published form of this manuscript, or allow others to do so, for United States Government purposes. The Department of Energy will provide public access to these results of federally sponsored research in accordance with the DOE Public Access Plan (http://energy.gov/downloads/doe-public-access-plan). The views and opinions of the authors expressed herein do not necessarily state or reflect those of the United States Government or any agency thereof. Neither the United States Government nor any agency thereof, nor any of their employees, makes any warranty, expressed or implied, or assumes any legal liability or responsibility for the accuracy, completeness, or usefulness of any information, apparatus, product, or process disclosed, or represents that its use would not infringe privately owned rights.

\section{REFERENCES CITED}

Baumberger, S., Dole, P., and Lapierre, C. (2002). "Using transgenic poplars to elucidate the relationship between the structure and the thermal properties of lignins," Journal of Agricultural and Food Chemistry 50(8), 2450-2453. DOI: 10.1021/jf0113530

Bhagia, S., Nunez, A., Wyman, C. E., and Kumar, R. (2016). "Robustness of two-step acid hydrolysis procedure for composition analysis of poplar," Bioresource Technology 216, 1077-1082. DOI: 10.1016/j.biortech.2016.04.138

Bhagia, S., and Ragauskas, A. J. (2020). "Preserving aryl ether linkages and higher yields of isolated lignin through biomass fibrillation," ACS Sustainable Chemistry \& Engineering 8(1), 34-37. DOI: 10.1021/acssuschemeng.9b06390

Bodîrlău, R., Teacă, C.-A., and Spiridon, I. (2007). "Thermal investigation upon various composite materials," Revue Roumaine De Chimie, 52(1-2), 153-158.

Delgado-Aguilar, M., González, I., Tarrés, Q., Pèlach, M. À., Alcalà, M., and Mutjé, P. (2016). "The key role of lignin in the production of low-cost lignocellulosic nanofibres for papermaking applications," Industrial Crops and Products 86, 295300. DOI: 10.1016/j.indcrop.2016.04.010

Diop, C. I. K., Tajvidi, M., Bilodeau, M. A., Bousfield, D. W., and Hunt, J. F. (2017). "Isolation of lignocellulose nanofibrils (LCNF) and application as adhesive replacement in wood composites: Example of fiberboard," Cellulose 24(7), 30373050. DOI: $10.1007 / \mathrm{s} 10570-017-1320-\mathrm{z}$

Espinosa, E., Sánchez, R., Otero, R., Domínguez-Robles, J., and Rodríguez, A. (2017). "A comparative study of the suitability of different cereal straws for lignocellulose nanofibers isolation," International Journal of Biological Macromolecules 103, 990999. DOI: 10.1016/j.ijbiomac.2017.05.156 
Espinosa, E., Tarrés, Q., Delgado-Aguilar, M., González, I., Mutjé, P., and Rodríguez, A. (2016). "Suitability of wheat straw semichemical pulp for the fabrication of lignocellulosic nanofibres and their application to papermaking slurries," Cellulose 23(1), 837-852. DOI: 10.1007/s 10570-015-0807-8

Gašparovič, L., Koreňová, Z., and Jelemenskỳ, L. (2010). "Kinetic study of wood chips decomposition by TGA," Chemical Papers, Springer, 64(2), 174-181. DOI: 10.2478/s11696-009-0109-4

He, M., Yang, G., Chen, J., Ji, X., and Wang, Q. (2018). "Production and characterization of cellulose nanofibrils from different chemical and mechanical pulps," Journal of Wood Chemistry and Technology 38(2), 149-158. DOI: 10.1080/02773813.2017.1411368

Hoeng, F., Denneulin, A., and Bras, J. (2016). "Use of nanocellulose in printed electronics: A review," Nanoscale 8(27), 13131-13154. DOI: 10.1039/C6NR03054H

Horseman, T., Tajvidi, M., Diop, C. I. K., and Gardner, D. J. (2017). "Preparation and property assessment of neat lignocellulose nanofibrils (LCNF) and their composite films," Cellulose 24(6), 2455-2468. DOI: 10.1007/s10570-017-1266-1

Iwamoto, S., Yamamoto, S., Lee, S. H., and Endo, T. (2014). "Solid-state shear pulverization as effective treatment for dispersing lignocellulose nanofibers in polypropylene composites," Cellulose 21(3), 1573-1580. DOI: 10.1007/s10570-0140195-5

Kumar, N., and Kumbhat, S. (2016). Essentials in Nanoscience and Nanotechnology, John Wiley \& Sons, Hoboken, NJ, USA.

Kumar, V., Bollström, R., Yang, A., Chen, Q., Chen, G., Salminen, P., Bousfield, D., and Toivakka, M. (2014). "Comparison of nano- and microfibrillated cellulose films," Cellulose 21(5), 3443-3456. DOI: 10.1007/s10570-014-0357-5

Leech, H. J. (1954). "An investigation of the reasons for increase in paper strength when locust bean gum is used as a beater adhesive," TAPPI Journal 37(8), 343-349.

MacLeod, M. (2007). “The top ten factors in kraft pulp yield," Paperi ja Puu [Paper \& Timber] 89(4), 1-7.

Marton, J. (1996). "Dry-strength additives," in: Paper Chemistry, J. C. Roberts (ed.), Springer Netherlands, Dordrecht, Netherlands, pp. 83-97.

Masuda, T. (1997). "High-speed pulverizing method and equipment," U. S. Patent No. 5620145A.

Morales, L. O., Iakovlev, M., Martin-Sampedro, R., Rahikainen, J. L., Laine, J., Van Heiningen, A., and Rojas, O. J. (2014). "Effects of residual lignin and heteropolysaccharides on the bioconversion of softwood lignocellulose nanofibrils obtained by $\mathrm{SO}_{2}$-ethanol-water fractionation," Bioresource Technology 161, 55-62. DOI: 10.1016/j.biortech.2014.03.025

Nair, S. S., Kuo, P. Y., Chen, H., and Yan, N. (2017). "Investigating the effect of lignin on the mechanical, thermal, and barrier properties of cellulose nanofibril reinforced epoxy composite," Industrial Crops and Products 100, 208-217. DOI: 10.1016/j.indcrop.2017.02.032

Olsson, A. M., and Salmén, L. (1997). "The effect of lignin composition on the viscoelastic properties of wood," Nordic Pulp \& Paper Research Journal 12(3), 140144. DOI: 10.3183/npprj-1997-12-03-p140-144

Rojo, E., Peresin, M. S., Sampson, W. W., Hoeger, I. C., Vartiainen, J., Laine, J., and Rojas, O. J. (2015). "Comprehensive elucidation of the effect of residual lignin on the 
physical, barrier, mechanical and surface properties of nanocellulose films," Green Chemistry 17(3), 1853-1866. DOI: 10.1039/C4GC02398F

Sánchez, R., Espinosa, E., Domínguez-Robles, J., Loaiza, J. M., and Rodríguez, A. (2016). "Isolation and characterization of lignocellulose nanofibers from different wheat straw pulps," International Journal of Biological Macromolecules 92, 10251033. DOI: 10.1016/j.ijbiomac.2016.08.019

Sethi, J., Visanko, M., Österberg, M., and Sirviö, J. A. (2019). “A fast method to prepare mechanically strong and water resistant lignocellulosic nanopapers," Carbohydrate Polymers 203, 148-156. DOI: 10.1016/j.carbpol.2018.09.037

Siró, I., and Plackett, D. (2010). "Microfibrillated cellulose and new nanocomposite materials: A review," Cellulose 17(3), 459-494. DOI: 10.1007/s10570-010-9405-y

Sluiter, A., Hames, B., Ruiz, R., Scarlata, C., Sluiter, J., Templeton, D., and Crocker, D. (2012). Determination of Structural Carbohydrates and Lignin in Biomass (NREL/TP-510-42618), National Renewable Energy Laboratory, Golden, CO, USA.

TAPPI T494 om-01 (2006). "Tensile properties of paper and paperboard," TAPPI Press, Atlanta, GA, USA.

Tarrés, Q., Ehman, N. V., Vallejos, M. E., Area, M. C., Delgado-Aguilar, M., and Mutjé, P. (2017). "Lignocellulosic nanofibers from triticale straw: The influence of hemicelluloses and lignin in their production and properties," Carbohydrate Polymers 163, 20-27. DOI: 10.1016/j.carbpol.2017.01.017

Van de Steeg, H. G. M., De Keizer, A., Stuart, M. A. C., and Bijsterbosch, B. H. (1993). "Adsorption of cationic amylopectin on microcrystalline cellulose," Colloids and Surfaces A: Physicochemical and Engineering Aspects 70(1), 77-89. DOI: 10.1016/0927-7757(93)80498-4

Van Heiningen, A. (2006). "Converting a kraft pulp mill into an integrated forest biorefinery," Pulp and Paper Canada 107(6), 38-43.

Visanko, M., Sirviö, J. A., Piltonen, P., Sliz, R., Liimatainen, H., and Illikainen, M. (2017). "Mechanical fabrication of high-strength and redispersible wood nanofibers from unbleached groundwood pulp," Cellulose 24(10), 4173-4187. DOI: 10.1007/s10570-017-1406-7

Xu, K., Shi, Z., Lyu, J., Zhang, Q., Zhong, T., Du, G., and Wang, S. (2020). "Effects of hydrothermal pretreatment on nano-mechanical property of switchgrass cell wall and on energy consumption of isolated lignin-coated cellulose nanofibrils by mechanical grinding," Industrial Crops and Products 149, 112317. DOI:

10.1016/j.indcrop.2020.112317

Article submitted: September 7, 2020; Peer review completed: October 25, 2020; Revised version received and accepted: November 5, 2020; Published: November 13, 2020.

DOI: $10.15376 /$ biores.16.1.209-222 